\title{
O BANZO, UM CONCEITO EXISTENCIAL: UM AFROPERSPECTIVISMO FILOSÓFICO DO EXISTIR-NEGRO
}

\author{
Marcos da Silva e Silva ${ }^{1}$ \\ Instituto Federal de São Paulo (IFSP) \\ https://orcid.org/0000-0003-1708-7782
}

\section{RESUMO:}

Sempre que falamos em Filosofia nos reportamos ao pensamento europeu como o centro das grandes reflexões filosóficas, o que em muita medida está correto. Porém, muito além do pensar a filosofia em um único centro é importante abrir possibilidades a partir dele, pois há novos diálogos e encruzilhadas epistêmicas a serem feitas na Filosofia. $\mathrm{O}$ texto que aqui apresentamos propõe pensar conceitos Afro como uma forma de fazer Filosofia. Neste caso, proponho analisar o conceito Banzo de maneira afroperspectivista. Para isso, partirei da Filosofia Africana e Afro-brasileira em um recorte fenomenológico-existencial, a saber: O Banzo compreendido enquanto conceito existencial.

PALAVRAS CHAVE: Banzo; Existência; Filosofia Africana.

\section{BANZO, AN EXISTENTIAL CONCEPT - AN AFRO PERSPECTIVISM PHILOSOPHICAL OF BEING AN AFRO-DESCENDANT PERSON}

\begin{abstract}
:
When we talk about Philosophy, we report to the European thinking as the center of a great phylosophical reflexion, that's correct in part of it. Althought, more than thinking the Philosophy as the center, it's importante to open possibilities from it, because there are new dialogues and epistemics crosses to be done in the Philosophy.

The text below proposes to think about an Afro concepts like a way to do Philosophy. In this situation, We propose to analyse Banzo concept in the way Afro perspectivism. Therefore, we get to start of an African Philosophy and Afro Brazilian into an existential phenomenological to know: Banzo is understood as an existencial concept.
\end{abstract}

KEYWORDS: Banzo, Existence, Philosophy, African

\footnotetext{
1 Professor do Instituto Federal de São Paulo (IFSP), São Paulo - Brasil. E-mail: freemarcos1@yahoo.com.br
}

SILVA, Marcos da Silva e. O banzo, um conceito existencial: um afroperspectivismo filosófico do existir-negro. Griot : Revista de Filosofia, Amargosa/Bahia, v.17, n.1, p.48-60, junho/2018. 


\section{Introdução}

O desejo de morrer e o desgosto pela vida sentido pelo escravizados são atribuídos pelos narradores colonos durante o processo de escravização no Brasil às reações nostálgicas decorrentes da perda da liberdade e dos vínculos com a terra e grupo social de origem, ainda aos castigos excessivos impostos. Os relatos de Oliveira Mendes (1817) que me reporto, referem-se a aspectos psicopatológicos, compreendidos como referências e enunciados sobre o páthos-negro tanto no sentido de paixões quanto de sofrimento, dor, adoecimento humana ou doença para morte. Nestes relatos, destacam-se questões nitidamente filosóficas como as características afetivas e morais dos africanos: (amor, ódio, constância, justeza, honra) e suas relações com instituições sociais como a família e o casamento, suas formas de reagir às vicissitudes do cativeiro, assim como relatos sobre o que se consideravam propriamente doenças físicas. A relação de todos os relatos e sentidos dados ao sofrimento negro, bem como suas consequências no comportamento atribui-se o conceito Banzo². Neste texto darei ao Banzo um status filosófico existencial afroperspectivista.

É necessário dizer que um estudo do Banzo como foi compreendido por pelos relatos precisa ser reinterpretado e refletido a partir da compreensão que os negros escravizados tinham a esse respeito, assim como, articular a história social da escravidão no Brasil, a história das teorias médicas europeias às questões filosóficas existências sobre as relações entre paixões, melancolia e morte voluntária e seus desdobramentos em terras brasileiras - o que incluiria as relações supostas entre clima, raça e psicopatologia - considerando também a circulação do discurso entre os negros letrados ou em suas narrativas ancestrais por meio da oralidade.

Do ponto de vista da história das teorias médicas, seria preciso verificar as conexões da concepção de Banzo como: melancolia, nostalgia e contemporaneamente à psicopatologia abordados por Frantz Fanon e a angústia como concepção existencial que, de acordo com este autor:

\footnotetext{
Por outras palavras, nossos atos não cessam nunca de nos perseguir. Seu arranjo, sua ordenação, sua motivação podem perfeitamente aparecer $a$ posteriori profundamente modificados. Não é esta uma das menores armadilhas que nos prepara a História com suas múltiplas determinações. Mas podemos escapar à vertigem? Quem ousaria supor que a vertigem não assedia toda a existência? (FANON, p. 215, 1961).
}

Essas reflexões ganham fôlego se pensarmos junto a elas as contribuições de Achille Mbembe em um diálogo saudável com o filosofar africano na contemporaneidade. E também, já que o curioso "suicídio por ingestão de terra" é citado com certa frequência ainda hoje, determinar como a morte voluntária entre os cativos foi associada a condições mórbidas em que existia a geofagia, o vício de comer terra (opilação/hipoemia, intertropical/ancilostomose). Por meio de uma

\footnotetext{
${ }^{2}$ No Novo Dicionário Banto do Brasil de Nei Lopes existem três definições sobre este conceito dentre eles a que mais se refere ao páthos-negro trás a seguinte definição: banzo; nostalgia mortal que acometia negros africanos escravizados no Brasil// adj. triste, abatido, pensativo, (3) Surpreendido, pasmado; sem jeito; sem graça (BH). Do quicongo mbanzu, saudade, paixão, mágoa. (Lopes, 2012).
}

SILVA, Marcos da Silva e. O banzo, um conceito existencial: um afroperspectivismo filosófico do existir-negro. Griot : Revista de Filosofia, Amargosa/Bahia, v.17, n.1, p.48-60, junho/2018. 
leitura política filosófica entenderemos o ato como a afirmação de que toda identidade humana (africana) é construída e histórico-cultural de toda existência e o Banzo seria a negação do seu contrário.

Pensar o Banzo em uma leitura afroperspectivista é refletir não apenas um conceito, é contextualiza-lo em seu significado dentro da história e na história dos africanos que sofreram de melancolia, da nostalgia angustiante, da doença para morte, ou, que vivenciavam um movimento único em torno do seu Lar Racial (APPIAH, 1997). As definições que o conceito Banzo nos traz, permite entende-lo para além do estado físico-psíquico em que os negros escravizados se encontravam ao chegar no Brasil, o Banzo é um conceito que aqui passarei a entender a partir de um Afroperspectivismo Filosófico, caracterizado por uma condição existencial, tendo, por conseguinte, uma expressão nas estruturas raciais neoliberais em que vive homem negro contemporâneo. Neste caso, é intemporal. Ou seja, é também ancestral.

Nosso pressuposto em refletir filosoficamente estas questões tem por base uma afrocentricidade analítica da Filosofia Africana, no intuito de se propor uma leitura que coloque segundo Molefi Kete Asante (1980), o Paradigma Afrocêntrico e sua problematização numa busca incessante por significados e sentidos do que foi e do que é o sofrimento do negro em uma realidade muitas vezes percebida como aparentemente destituída dele. No decorrer do tema central, mesmo que a contrapelo, é possível vislumbrar a relevância de pensadores e pensamentos africanos na diáspora da História da Filosofia ${ }^{3}$.

Ao assumir uma leitura que se mantenha nessa ótica, pretendo refletir sobre a possibilidade de formação de um quadro referencial e conceitual que seja amplo o bastante para permitir compreender significações amplas das estruturas simbólicas, sociais e epistêmicas criadas e reiteradas a respeito da Filosofia Africana que nas mais diversas diásporas, têm oferecido ao pensamento contemporâneo uma produção efusiva, em muitos casos libertadora dos racismos e dos preconceitos epistêmicos. Uma vez compreendida o filosofar como libertação, caminhamos para uma relação saudável com a história geral da filosofia e o lugar que o Banzo deve ocupar enquanto conceito filosófico.

\section{É preciso definir: existe uma filosofia africana ${ }^{4}$ ?}

A Filosofia Africana é usada de múltiplas formas por diferentes filósofos. Embora muitos filósofos africanos tenham contribuído para diversas modos do filosofar africano. Por isso, uma grande parte da literatura entra em debate para discutir se a filosofia africana de fato existe. Defendo sua existência, e creio que devemos caminhar para habilitação de uma filosofia afro-brasileira impulsionados também pelas pesquisas africanas afrodiaspóricas, chegando, quando possível, a uma sociedade intercultural não hierarquizada como uma alternativa do pensar descolonizado.

\footnotetext{
${ }^{3}$ Renato Nogueira. O ensino de Filosofia e a lei 10.639. Rio de Janeiro: Pallas/Biblioteca Nacional, 2014, p. 68-69.

${ }^{4}$ Um dos mais básicos motivos de discussão sobre a evidencia da Filosofia Africana giram em torno da aplicação do termo "africano", que segundo Appiah (1997) passa a ser explorado pelas correntes panafricanistas e do pan-negrismo.
}

SILVA, Marcos da Silva e. O banzo, um conceito existencial: um afroperspectivismo filosófico do existir-negro. Griot : Revista de Filosofia, Amargosa/Bahia, v.17, n.1, p.48-60, junho/2018. 
Ao pensar a Filosofia Africana devemos discutir linhas e correntes filosóficas que antecedem nossa reflexão, como: Filosofia africana pré-moderna, que segundo a definição de Joseph I. Omoregbe: o filosofo é o pensar habitual que reflete sobre os fundamentos e questões da vida humana e o universo físico. Essa forma de pensar o filosofar estaria muito próximo das considerações de Gramisci e Deleuze ${ }^{5}$. O primeiro considera que todos são "filósofos", mas não são especialistas, já Deleuze pensa o filósofo como criador de conceitos passando à criação de filosofia.

Henry Odera Oruka defende uma Filosofia africana moderna. Esse pensador amplia as reflexões e chama atenção para quatro tendências na filosofia africana moderna: etnofilosofia, sagacidade filosófica, filosofia ideológica nacionalista e filosofia profissional. Mais tarde, Oruka adicionaria ainda mais duas categorias: a filosofia literária/artística, que teve representantes como Ngugi wa Thiongo, Wole Soyinka, Chinua Achebe, Okot p'Bitek, e Taban Lo Liyong; e a filosofia hermenêutica. Maulana Karenga é um dos principais filósofos dessa linha.

Placide Tempels defende a proposta do termo etnofilosofia que designa as crenças encontradas nas culturas africanas. Essa proposta consiste em um conjunto de crenças, valores e pressupostos que estão implícitos na linguagem, práticas e crenças da cultura africana e como tal, é visto como um item de propriedade comum. Placide Tempels argumenta em favor da filosofia bantu que segundo ele, a metafísica do povo Bantu são refletidas em suas linguagens. Neste caso, são as línguas que refletem o pensamento na África ${ }^{6}$. Contrário a essa forma de pensar, a Filosofia Profissional é a visão europeia de pensar, refletir e raciocinar, já que tal forma é relativamente nova na maioria da África. Essa visão seria a resposta mais comum da maioria dos filósofos ocidentais.

A filosofia ideológica nacionalista, assim como pan-africanismo pode ser vista como filosofia política, o que em muito sentido se aproxima da realidade brasileira ou de uma filosofia afro-brasileira. Seja na Filosofia Africana ou no nosso modo de fazer filosofia, um mesmo tipo de problema surge: é preciso manter uma distinção entre ideologia, filosofia e conjuntos de ideias de uma maneira especial de raciocínio, ou razão como nos fala Mbembe na Crítica da Razão Negra (2017).

O caminho que abre as portas para a compreensão do universo do pensamento filosófico deste texto é a de uma filosofia Africana e afro-brasileira. No entanto, como já ilustramos, seu contexto é latino-americana. A esse caminho podemos ser favorecidos por uma Filosofia da Libertação e nisso, Enrique Dussel nos dá seguinte contribuição:

Sem querer me arrogar do direito de representar um movimento amplo, a Filosofia da Libertação, que eu ponho em prática desde 1969, toma como ponto de partida uma realidade regional própria: a pobreza crescente da

\footnotetext{
${ }^{5}$ O professor Daniel Pansarelli (2013) chama a nossa atenção para uma filosofia nacional e latinoamericana pensada por Enrique Dussel. Em suas palavras: "Neste contexto de busca pela produção filosófica autenticamente relacionada ao ethos e às razões mais próprias aos povos do nosso continente é que se insere a produção filosófica de Enrique Dussel, autor da obra que serve ao mesmo tempo como objeto de estudos e motivador de uma produção filosófica-cultural crítica" (Pansarelli, 2013, p. 21).

6 É importante sabermos que a África não pode ser entendida como um todo homogêneo, sendo formada por diversas tradições que são subdivididas em tantas outras.
}

SILVA, Marcos da Silva e. O banzo, um conceito existencial: um afroperspectivismo filosófico do existir-negro. Griot : Revista de Filosofia, Amargosa/Bahia, v.17, n.1, p.48-60, junho/2018. 
maioria da população latino-americana, a vigência de um capitalismo dependente, que transfere valores para o capitalismo central, a tomada de consciência da impossibilidade de uma filosofia autônoma dentro dessas circunstâncias a existência de tipos de opressão que estão a exigir não apenas uma filosofia da "liberdade", mas uma filosofia da "libertação" (em forma de ação, em forma de práxis, cujo o ponto de partida é a opressão e cujo a meta a atingir é a libertação, já indicada, por exemplo, no machismo ancestral enquanto opressão da mulher etc). (DUSSEL, 1995, p. 45-46.).

É preciso repensar o filosofar, isto é, a maneira como os pesquisadores elaboram em quadros metodológicos mais ou menos definidos pelo modelo eurocêntrico, do colonizador, todo conhecimento e a prática do filosofar que trazem consigo, suas representações nas vivências e experiências cotidianas de investigação cientifica, traduzindo as percepções da realidade por intermédio do senso comum, sem contudo, considerar as particularidades das tradições Afro e latino-americana em seu caráter epistêmico. A episteme constituída a partir de uma reflexão filosófica de matriz Africana e afro-brasileira é o que nos permite pensar o conceito Banzo enquanto conceito existencial e por meio dele formar o ponto na Filosofia.

\section{O Banzo: um conceito filosófico}

Pensar a Filosofia Africana e afro-brasileira a partir do conceito Banzo é uma forma de raciocínio que estabelece a construção e/ou assimilação de conceitos e imagens sobre pessoas, papeis e fenômenos do cotidiano dos escravizados onde se estruturavam e estruturam a condição existencial do negro, a partir das quais derivam as leituras que se propõem reflexões de contextos, nos mais diversos níveis de exclusão causados pelo colonialismo e neocolonialismo, bem como dos aspectos particularizadores da parcela de angustia ou nostalgia que cada indivíduo excluído da sua pátria e identidade passou a constituir como uma condição existencial.

Minha intuição diz que dentro deste tema devemos investigar, na Filosofia Africana a relação entre o que pode subsistir fora do conhecimento submetido ao colonizador (e que é metafísico: o Banzo com coisa em si) e o que está submetido aos princípios de determinação do fenômeno (por sua vez, físico: o Banzo como efusão de um modo de existir do negro no Brasil). Isto pode ser percebido, a título de exemplo, nas manifestações "civilizatórias" pós-colonial e pós-moderna ${ }^{7}$, em que as colônias se converteram num mercado. Ou mesmo como nos complementa Mbembe:

E não é tudo. Produto de uma máquina social e técnica indissociável do capitalismo, da sua emergência e globalização, este nome foi inventado para significar exclusão, embrutecimento e degradação, ou seja, um limite sempre conjurado e abominado. Humilhado e profundamente desonrado, o

\footnotetext{
${ }^{7}$ Se seguirmos o que diz Lyotard (2002) e Harvey (2002): O Pós-colonialismo centrou-se praticamente em três grandes vertentes: a antropologia, a literatura e a história. A filosofia praticamente ausentouse dessa perspectiva, não se interrogando sobre os fundamentos do racismo, deixando que a antropologia discutisse como ele funciona e que a literatura, juntamente com a história, buscasse pelos múltiplos significados de sua existência, ora num plano horizontal, ora no vertical. Uma perspectiva de conjunto talvez não caiba nos tempos de pós-modernidade.
}

SILVA, Marcos da Silva e. O banzo, um conceito existencial: um afroperspectivismo filosófico do existir-negro. Griot : Revista de Filosofia, Amargosa/Bahia, v.17, n.1, p.48-60, junho/2018. 
negro é na ordem da modernidade, o único de todos os humanos cuja a carne foi transformada em coisa, e o espírito, em mercadoria - a cripta viva do capitalismo (MBEMBE, 2017, p.19).

Neste sentido o Ser-Negro enquanto condição existencial é marcada por uma busca de apropriação satisfatória do lugar de si, de uma postura, segunda a qual, cada negro a partir de seu Lar de Ser, pode considerar-se uma representação ou um produto dos desdobramentos do confronto, tanto da colonização como do capitalismo, por vezes violenta, como destaca Fanon: "A violência é, dessa maneira, compreendida como mediação regia. $O$ homem colonizado liberta-se na e pela violência. Estas práxis ilumina o agente porque lhe indica os meios e o fim". (FANON, 2009, p. 66). Os novos aspectos da violência já não se apresentam pelo atos explícitos de causar dor e morte ao negro escravizado, uma das formas em que essa violência se manifesta é pelo ato de violar direitos, o que atinge diretamente a vida dos negros, nesta conjuntura não é necessário por vezes esfolar diretamente a carne do negro, permite-se apenas que os modelos globalizados de economia neoliberal faça o trabalho sem que os neo-colonos manchem seus vistos e passaportes com a morte dos negros, seja na África, no Brasil ou na América -Larina como um todo. Ainda prevalece o status quo do modo de existir do negro, sendo assim, o Banzo perpassa o tempo linear da história, o Banzo é então ancestral, na medida em que a representação real da condição existencial do Ser-Negro perdura.

A noção de Banzo, retomada para uma análise afrocêntrica existencial, parece caminhar numa espécie de contramão do processo de construção do sentido de existir do negro. Uma vez que na visão de Appiah há uma semelhança entre o sofrimento dos negros e o sofrimento dos judeus. A diferença é: para o segundo, há uma filosofia existencial. Podemos mensurar a partir das produções de Heidegger, Hannah Arendt e Sartre, apenas a título de exemplo. Discutir existencialismo é também discutir racismo, é uma resposta a esse sentimento de marginalização racial e existencial.

A percepção das macroestruturas para realizar um vocabulário marxista que parece reatualizar-se na Filosofia Africana, pressupõe um contato íntimo com o grupo no qual os homens são acolhidos e com o qual estabelecem relações intricadas por meio das conversas, das visões, das crenças, dos mitos e dos ritos que veiculam na produção da vida. Na visão de Appiah trata-se do nacionalismo, da relação entre nação, literatura e raça. Há, neste caso, a necessidade de diálogo como o programa afrocentrista, que para (Asante 2009), tem um lugar.

Tendo sido os africanos deslocados em termos culturais, psicológicos, econômicos e históricos, é importante que qualquer avaliação de suas condições em qualquer país seja feita com base em uma localização centrada na África e sua diáspora. Começamos com a visão de que a afrocentricidade é um tipo de pensamento, prática e perspectiva que percebe os africanos como sujeitos e agentes de fenômenos atuando sobre sua própria imagem cultural de acordo com seus próprios interesses humanos. (ASANTE, 2009, p. 39).

Vendo o Sentido de Ser-Africano para além de seu local geográfico passamos a entender que o sentido do Ser Africano se encontra em sua própria identidade existencial a partir de sua identidade local. Por meio disso, o sujeito africano pode

SILVA, Marcos da Silva e. O banzo, um conceito existencial: um afroperspectivismo filosófico do existir-negro. Griot : Revista 
ser entendido como uma identidade existencial ou a partir de conceitos que definem essa identidade.

\section{Repensar conceitos, criar conceitos e fazer filosofia}

Partindo desse microuniverso do conceito Banzo, passa-se a um outro estádio: a necessidade de se reelaborarem conceitos e imagens anteriormente apreendidos e que, por sua vez, acabam por ser aceitos, naturalizados, considerados verdadeiros, muito embora continuem permanecendo como simples representações da condição existencial do negro escravizado no Brasil.

Repensar o Banzo parece justificar-se por uma volta ao universo referencial proposto, uma vez que a compreensão desse multifacetado complexo entendimento sobre o Banzo, sentido pelos negros escravizados, oferece uma oportunidade pela ancestralidade não só de se compreender os caminhos, e encruzilhadas, que têm marcado a contemporaneidade, como também, pode apontar para propostas de elaborações de uma afrocentricidade analítica na compreensão dos discursos que têm marcado a realidade atual pela negação ou afirmação de uma Filosofia Africana e afro-brasileira num contexto Latino-Americano a partir dos modos de Ser e existir do negro.

A problemática proposta em foco por este texto, bem como seu objetivo principal, torna necessário que se reflita de forma ampla sobre o estatuto epistemológico da Filosofia. Nisso, é preciso aproximar, como já indicamos, a Filosofia Africana e afro-brasileira de uma Filosofia Latino-americana ou dos filósofos que permitem esse diálogo. Na Filosofia Africana se destacam: Marcien Towa, l'idée d'une philosophie négro- africaine, Editions CLE, Yaoundé, 1979. Etienne BBBE- NJOH, Mentalité africaine et problématique du développement, Paris, Editions L'Harmattan ,2002. Eboussi Boulaga, la crise du Muntu. Authenticité africaine et philosophie, Paris Editions Présence Africaine ,1977. Cheikh Anta Diop, Antériorité des civilisations nègres. Mythe ou vérité historique? Paris , Editions présence Africaine, 1987. Théophile Obenga, La philosophie africaine de la période pharaonique 2780 -330 avant notre ère, Paris, Editions L'Harmattan, 1990, Kwame Anthony Appiah, Na casa do meu pai. A África na filosofia da cultura. Rio de Janeiro: Contraponto, 1997; Frantz Fanon, Os condenados da terra. trad. Enilce A. Rocha e Lucy Magalhães, Juiz de Fora: EdUFJF, 2009.

No Brasil são poucas as vozes que discutem uma filosofia afro-brasileira, destacamos aqui os trabalhos de Abdias Nascimento (2014). Uma das principais preocupações desse pensador foi o que ele chama de descolonização mental dando destaque ao conceito de quilombismo que é uma releitura da negritude e do PanAfricanismo. Ainda atuante em sua pesquisa o professor Renato Nogueira tem uma preocupação como os trabalhos acadêmicos que sejam afrodiaspóricos em prol da desconstrução do Racismo Epistêmico. Como proposta de combate a esse racismo, Renato Nogueira apresenta na obra O Ensino de Filosofia e a Lei 10.639 (2011) referencias teóricas, sugestões práticas para um ensino de filosofia afro-brasileiro. Vale ressaltar também os trabalhos do professor Eduardo Oliveira que traz com muito vigor o tema da Ancestralidade. Para Oliveira, "a Filosofia da Ancestralidade está na encruzilhada do pensamento contemporâneo". (Oliveira, 2012). Se destacam

SILVA, Marcos da Silva e. O banzo, um conceito existencial: um afroperspectivismo filosófico do existir-negro. Griot : Revista 
ainda Boaventura de Sousa Santos e Meneses (2010). E somos seremos favorecidos com os trabalhos de Marcos Nobre (2000), Roberto Gomes (2012) e Julio Cabrera (2013). Já na filosofia latino-americana, nos reportamos aos trabalhos de Enrique Dussel (1993), Salazar Bondy (1988), Zea (1975) e Daniel Pansarelli (2013).

O desenvolvimento temático da compreensão do Banzo a partir dos referenciais teóricos que apresentamos acima e entendidos enquanto conceito existencial poderia ser estabelecido por três linhas de pensamento: a primeira pode propor a compreensão da Filosofia Africana e como ela se coloca diante da História da Filosofia eurocêntrica, especialmente nos trabalhos de Kwame Anthony Appiah (1997) e Kete Molefi Asante (1987) e Cheikh Anta Diop (1987) nos quais se pode-se ver uma preocupação crescente com as estruturas da afrocentricidade, identidade e colonialismo, o que permite assentir ou recusar uma filosofia tipicamente africana. $O$ apoio interpretativo pode ser buscado nos trabalhos de Abdias Nascimento e Emmanuel Cukwudi Eze (2001). A segunda linha abre-se em duas vertentes, distintas, mas próximas em suas ocupações. A primeira vertente poderia ser uma atualização do status da discussão sobre o Banzo do homem negro escravizado e estão centradas no pensamento de Luiz Antônio de Oliveira Mendes (1817) enquanto narração e Frantz Fanon (1961) como interprete das patologias sob uma olhar fenomenológico-existencial analítico feito a contrapelo. Em Fanon os trabalhos podem depreender a importância que atribui ao sofrimento psicopatológico na vida dos negros. A terceira vertente surge como fonte analítica afrocêntrica do Banzo em perspectiva existencial, aqui pode-se exercitar a contrapelo o caminho proposto por Kierkegaard, Heidegger e Sartre propondo o Banzo enquanto conceptualização existencial filosófica contemporânea.

A escolha desse referencial teórico pelo prisma fenomenológico-existencial como uma das fundamentações possíveis para esta reflexão justifica-se por permitir a compreensão de uma determinada situação subjetiva e social a partir da perspectiva que Lewis Gordon (2011) nos leva a pensar. Em escritos, a fenomenologia especialmente de matriz husserliana - funde-se à teoria crítica da raça, à sociologia existencial e ao pensamento de Marx, Du Bois e Fanon para compor o que NissimSabat denomina como " new postcolonial humanism" (Nissim-Sabat, 2011). Deste modo busca equacionar tanto os aspectos concretos quanto os (inter) subjetivos da realidade social os modos de existir. A influência hursserliana pode ser percebida em sua aposta na fenomenologia como um método de investigação da realidade contemporânea. Para ele:

\footnotetext{
Phenomenological appeals have the distinct advantage of recognizing intentional dimensions to human phenomena. The entail an appeal to the intersubjective foundations of meaning, to their constitutive features manifested in the realm of sociality. Moreover, like the textual appeals, phenomenological one's afford a space for openness by suspending ontological commitments to the phenomena beyond their status as phenomena (GORDON, apud NISSIM-SABAT, 2011, p. 43).
}

Assim a fenomenologia existencial proposta por Gordon que aqui propomos como recurso para pensar o Banzo permitiria refletir a respeito das humanidades (Geisteswissenschaft) como a negociação entre a interação existencial das pessoas individuais e a trajetória mais geral do mundo espiritual (Geist) em seu recorte 
ancestral da comunidade humana (Nissim-Sabat, 2011:35) mas, ao mesmo tempo, como acredita ser impossível apreender a ontologia final (a coisa em si, em termos kantianos) do mundo. Isso significa, segundo Nissim-Sabat, que a fenomenologia de Lewis Gordon representa um compromisso que é, ao mesmo tempo, humanista, em sua preocupação radical com a humanidade, e pós-colonial, em sua recusa ao racismo e aos essencialismos identitários. Como veremos, é a partir dessa perspectiva que apresentará tanto o racismo anti-negro como a própria identidade negra como expressões de autoengano.

A imagem do autoengano impossibilita uma abertura para construir as identidades negras enquanto condição existencial, tanto como modo de ser de fato quanto como um conceito existencial, aqui revogamos o Banzo sobre essas duas possibilidades, uma vez que o Banzo e seus significados são vistos como instrumentos de negação ao colonizador e um princípio de construção da identidade negra. "Os homens colonizados, esses escravos dos tempos modernos, estão impacientes. Sabem que só essa loucura pode subtrai-los à opressão colonial". (FANON, 1968: 56). Consequentemente as colonizações são fontes produtoras dos discursos racistas que permanecem no imaginário dos sujeitos no mundo da vida:

Para Dussel:

Colonização do mundo da vida não é aqui uma metáfora. A palavra tem
sentido forte, histórico, real (...) A colonização da vida cotidiana do nativo,
do escravo africano depois, foi o primeiro processo "europeu" de
"modernização" de civilização, de subsumir (ou alienar) o Outro como si
mesmo (...) É o começo da domesticação, estruturação, colonização do
"modo" como aquelas pessoas viviam e reproduziam a vida humana.
Sobre o efeito daquela "colonização" do mundo da vida se construirá a
América Latina posterior. (DUSSEL, 1993, p. 43)

Essa leitura permite uma aproximação compreensiva e compreensível da condição existencial (Banzo) que têm marcada as relações humanas no mundo globalizado contemporâneo chicoteadas pelo modelo neoliberal que mantem as relações de submissão do homem negro, seja na África ou no Brasil com o racismo ante-negro.

A este tipo interpretação das novas formas de Banzo (de modos de existência pautados no racismo e no sofrimento) o autor contemporâneo Achille Mbembe na obra Crítica da Razão Negra nos dá a seguinte reflexão: "Humilhado e profundamente desonrado, o Negro é, na ordem da modernidade, o único de todos os humanos cuja a carne foi transformada em coisa, e o espírito em mercadoria a cripta viva do capital" (Achille Mbembe, 2017, p: 19). Compartilho com esta afirmação por entender que a estrutura racista do período colonial ao mundo contemporâneo é ainda constituído pela submissão do homem negro, o que por sua vez perpassa a constituição de sua identidade existencial, ou seja, as representações do páthos do homem negro é ao mesmo tempo aquilo que se dá pelo seu modo de ser e estar no mundo.

Promover uma análise a respeito do Banzo enquanto conceito existencial nos leva a uma investigação mais ampla da Filosofia Africana e afro-brasileira em contexto latino-americano. Para tanto, é preciso traçar um caminho a ser percorrido no processo de compreensão do lugar que o Banzo ocupa, tanto no âmbito 
epistemológico, como no existencial-fenomenológico, uma vez que este conceito já constituía objetiva e subjetivamente os primórdios da história da escravidão, não sob a perspectiva existencial africana, mas pelo modo racista de entender a condição existencial do homem negro escravizado e por conceitos racistas que foram colocados como únicos para compreensão do sentido do existir do ser negro, reafirmando por sua vez o racismo epistêmico por meio da dominação da linguagem.

Até aqui foi preciso explicitar em um nível mais micro um resgate do Banzo a partir da Filosofia Africana sob uma roupagem conceitual contemporânea, uma vez que o Banzo não deixa de ter suas origens nas discussões que movimentavam o espírito dos africanos escravizados, quer circunscritos ao universo da própria África, quer nas ampliações que os colonizadores posteriores trouxeram na sua atual vertente neoliberal. Uma vez que as transformações do mundo capitalista na metade do século XX não apontam o fim do racismo ante negro, configurados no domínio da economia mundial, o que reforça a ideia de não pertencimento ao mundo globalizado. "Uma nova economia política de vida instala-se, irrigada pelos fluxos internacionais do saber e tendo como componentes privilegiados, também, as células, os tecidos, os órgãos, as patologias e as terapias, assim como a propriedade intelectual". (Mbembe, 2017, pp. 46-47) . São essas as resignações do Banzo enquanto condição de existência que se instala aos modos de vida do negro. A saber, o páthos negro se reconfigura no neoliberalismo.

\section{Existencialismo Afro-Filosófico}

É preciso pensar o sentido atribuído à condição existencial do homem negro instituído pelo colonizador. No entanto, mais importante que isso é entender como o próprio negro escravizado ou não, vive em sua condição existencial. Para tal feito, considero elaborações de metodologias e práticas de pesquisas e análises filosóficas existências que possam resgatar conceitos africanos para dar sentido ao modo de existir tanto dos negros escravizados no período colonial quanto ao modo de existir dos negros imersos no modelo neoliberal de vida.

Até aqui, se introduz uma investigação teórico e crítica sobre os aparatos metodológicos das estruturas do significado do Banzo enquanto conceito existencial e sua contribuição para o desenvolvimento das leituras existencialistas do Ser-negro, tanto no seu nascedouro: período de escravização (e a reflexão que me propus foi trabalhar um tipo de existencialismo que, como proposta, já se configura na Filosofia Africana na figura do Griô como o principal expoente dos modos de pensar), quanto nas correntes filosóficas da contemporaneidade, (e neste sentido abre-se como reflexão Latino-Americana e afro-brasileira). A estratégia metodológica adotada incita discussões mais amplas de temas relacionados à relação entre o Banzo e seu papel no contexto existencial e existente, desenvolvidos a partir de uma afrocentricidade analítica, crítica e reflexiva. Contudo, é preciso investigar a adequação e os limites da utilização do conceito Banzo dentro das produções filosóficas africanas; compatibilizando com os pressupostos de um pensar que se mostre efetivamente preocupado com a crítica às razões coloniais, desenvolvendo um estudo paralelo entre o papel central que o Banzo adquire no período colonial e em

SILVA, Marcos da Silva e. O banzo, um conceito existencial: um afroperspectivismo filosófico do existir-negro. Griot : Revista de Filosofia, Amargosa/Bahia, v.17, n.1, p.48-60, junho/2018. 
sua vertente contemporânea, especialmente nas discussões que preparam o filosofar libertador em seu recorte existencial.

Embora se trate de um texto de viés eminentemente teórico, a proposta de reflexão procura fundamentar-se social e ativamente nas vivências cotidianas como fontes provocadoras de discussões que se apresentam localizadas, quer em quilombos ou nas periferias brasileiras. Isso leva identificar na tradição de pensamentos filosóficos onde se inclui a Filosofia Latino-Americana? Quais correntes filosóficas ou filosofias nos oferenda, dentro da disporá, as produções do pensamento filosófico africano? O uso etimológico da linguagem, termos e conceitos que localizem de maneira crítica a origem de tais pensamento? Trata-se até este momento de uma genealogia e desconstrução, tendo o conceito Banzo como norteador. É preciso para isso, pesquisadores com um olhar focado na Filosofia, (com preocupação na Filosofia Africana) produzindo trabalhos acadêmicos que visem à compreensão da temática proposta sob diferentes óticas e em diferentes momentos históricos, tanto em nível de pesquisa como posteriormente em contribuição acadêmica e social.

\section{Conclusão da encruzilhada}

Uma boa parte das pesquisas em filosofia tende a limitar iniciativas que levem a outras formas de filosofar a partir da criação de novos conceitos. Essa racionalidade dominante tende a chamar de emocionais, intuitivas e imaginarias os recursos conceituais que derivam da ancestralidade africana como uma racionalidade hegemônica, mas, não menos filosófica.

\footnotetext{
Na esfera da racionalidade hegemônica, pequena margem é deixada para variedade, a criatividade, a espontaneidade. Enquanto isso, surge, nas outras esferas, contrarracionalidades e racionalidades paralelas corriqueiramente chamadas de irracionalidades, mas que na realidade constituem outras formas de racionalidade. (SANTOS,2011, p. 120-121).
}

É no processo da vida, das práticas e das teorias herdadas pela tradição que surgem novos conceitos para uma nova racionalidade. Se em Kant podemos falar em uma Crítica da Razão Pura, em Heidegger discutir Ser e Tempo ou Dasein, em Kierkegaard pensar $O$ Conceito de Angústia e o Desespero Humano. Por que não poderíamos falar em uma negação à nossa Razão Tupiniquin, como propõe Roberto Gomes (2012), e afirmar a Ancestralidade como filosofia, na leitura de Eduardo Oliveira (2007), pensar o negro por meio da Crítica da Razão Negra de Achille Mbembe ou ainda o Banzo como conceito existencial afroperspectivista? Devemos considerar, com Deleuze, que o filosofar passa pela criação de conceitos. Assim, é possível uma Filosofia Africana e afro-brasileiro não apenas como reprodução ou cópia, e sim a afirmação de uma outra razão.

Isso indicará numerosas frações de um filosofar libertador, que passará de uma situação de conformidade epistêmica associada ao conformismo acadêmico a uma etapa no ensino superior da produção de novos conceitos, isto é, de uma Filosofia Africana e afro-brasileira, da conformidade filosófica sem o conformismo no filosofar. Dessa maneira, será a redescoberta pelos pesquisadores e estudantes de uma outra razão, já existente, mas não explorada, e não é de se espantar que essa descoberta se dê nos espaços de resistência ao colonialismo mental, uma vez que na como proposta pedagógica o ensino da História e Cultura Afro-Brasileira garantido 
pela lei 10.639 te em seus objetivos o reconhecimento da cultura afro como identidade do povo negro no Brasil.

Os ingressos nas escolas públicas de educação básica, em sua maioria, trazem consigo as identidades étnicas, culturais, econômicas e sociais que não se conformem com a racionalidade dominante, o mesmo se reproduz no ensino superior, quando os estudantes são minoria. Estes são paradoxos da realidade brasileira apontados pela educação que não permite a elaboração de novas racionalidades de forma concreta.

Espera-se que essas novas razões sejam divulgadas não apenas como produto cultural, mas, como modo de ressignificação do sentido de existir do homem negro e uma forma de se fazer filosofia descolonizada. O resultado é uma imagem da Filosofia como um campo do saber em constante dinâmica e renovação. Nisso, reside um de seus diferenciais dentro do quadro da Filosofia no Brasil.

Uma vez que o objetivo primordial de qualquer reflexão é que se produzam críticas significativas e que estas sejam disponibilizados para a comunidade acadêmica e para o contexto sócio histórico mais amplo, vejo com relevância os resultados destas reflexões dando garantias de eficácia e da efetividade da Filosofia Africano e afro-brasileira, tanto quanto de sua utilidade para a comunidade acadêmica e de sua validade teórico e metodológica, uma vez que na tradição filosófica ocidental há poucas defesas de uma Filosofia Africana e afro-brasileira, seja por questões históricas, sociais ou econômicas que atingem a África e os países da américa-latina em função do racismo epistêmico neoliberal que impõe uma larga escala produção filosófica consistente na Europa como produtora de reflexões sobre a existência universal, abrindo mão da margem, (povos e países marginalizados).

Temos que firmar o ponto na perspectiva de uma Filosofia Africana e Afrobrasileira na América Latina, quebrar os grilhões epistêmicos que nos impede de caminhar em direção a uma autonomia de pensamento que seja de fato descolonizada e que ao mesmo tempo aponte os limites da racionalidade dominante descrito por Milton Santos (2011), e derruba o tronco do racismo epistêmico. Em outras palavras, concordando com Mbembe: "Possuídos por África, podemos finalmente mudar de identidade, quebrar as fronteiras da alteridade, superar os sentimentos da degradação, o desejo de suicídio e a angústia da morte". (MBEMBE, 2017, p.94). É por meio da ressignificação do Banzo, pensado enquanto um conceito existencial dentro da Filosofia Africana e Afro-brasileira que encontraremos identidade e autonomia intelectual, permitindo definir o sentido de Existir e SerNegro. 


\section{Referências bibliográficas}

APPIAH, Kwame Anthony. Na casa do meu pai: a África na filosofia da cultura. Rio de Janeiro: Contraponto, 1997.

ASANTE, Malefi. The Afrocentric Idea. Philadelphia: Temple University Press, 1987.

DUSSEL, E. 1492 o encobrimento do outro - A origem do mito da modernidade, São Paulo: Perseu Abramo, 1993.

Filosofia da Libertação: Crítica à Ideologia da Exclusão. São Paulo

Paulos. 1995.

FANON, Frantz. Os condenados da terra. Trad. Enilce A. Rocha e Lucy Magalhães, Juiz de Fora: EdUFJF, 2009.

EDUFBA, 2008.

- Pele negra máscaras brancas. Trad. Renato da Silva. Salvador:

MBEMBE, A. Crítica da razão negra. Lisboa: Antígona, 2017.

NOGUEIRA, Renato. O ensino de filosofia e a lei 10.639. Rio de Janeiro: CEAP, 2011.

OLIVEIRA, Eduardo D. Filosofia da ancestralidade: corpo e mito na filosofia da educação brasileira. Curitiba: Editora Gráfica Popular, 2007.

PANSARELLI, D. Filosofia Latino-Americana a partir de Enrique Dussel. Santo André: Universidade Federal do ABC, 2013.

SANTOS, M. Por uma outra globalização: do pensamento único à consciência universal. Rio de Janeiro: Record, 2011.

Autor(a) para correspondência: Marcos da Silva e Silva, Instituto Federal de São Paulo, R. Pedro Vicente, 625, CEP 01109-010 - Canindé, São Paulo - SP, Brasil. freemarcos1@yahoo.com.br 